\title{
Influence of Oil Palm Biomass Waste on Compressive Strength and Chloride Penetration of Mortar
}

\author{
Nor Hasanah Abdul Shukor Lim ${ }^{1}$, Mostafa Samadi ${ }^{1}$, Mohd Warid Hussin ${ }^{1}$, Abdul Rahman \\ Mohd Sam ${ }^{1}$, Nur Farhayu Ariffin ${ }^{2}$, Mohamed A. Ismail ${ }^{3}$, and Han Seung Lee ${ }^{4}$, and Mohd \\ Azreen Mohd Ariffin ${ }^{5}$ \\ ${ }^{1}$ Construction Research Centre (UTM CRC), Institute for Smart Infrastructure and Innovative \\ Construction, Faculty of Civil Engineering, Universiti Teknologi Malaysia, 81310 UTM Johor Bahru, \\ Johor, Malaysia \\ ${ }^{2}$ Faculty of Civil Engineering and Earth Resources, Universiti Malaysia Pahang, Lebuhraya 8 Tun \\ Razak, 26300 Kuantan, Pahang, Malaysia \\ ${ }^{3}$ Civil and Construction Engineering Department, Faculty of Engineering and Science, Curtin \\ University, Sarawak Malaysia, Miri, Sarawak, Malaysia \\ ${ }^{4}$ Department of Architectural Engineering, Hanyang University, Ansan, Republic of Korea \\ ${ }^{5}$ Forensic Engineering Centre, Institute for Smart Infrastructure and Innovative Construction, Faculty \\ of Civil Engineering, Universiti Teknologi Malaysia, 81310 UTM Johor Bahru, Johor, Malaysia
}

\begin{abstract}
The utilization of waste materials which are abundant and cheap, especially from clean resources, has become more pressing than ever. This study investigates the influence of Oil Palm Biomass waste including the Palm Oil Fuel Ash (POFA), Oil Palm Kernel Shell (OPKS) and Oil Palm Fibre (OPF) on the compressive strength and chloride penetration of mortar. The POFA was used as cement replacement up to $80 \%$ in nano size. The mass ratio of fine aggregates to binder was $3: 1$. Test specimens $70 \times 70 \times 70 \mathrm{~mm}$ cube were prepared and cured in water for 28 days. Ordinary Portland cement (OPC) mortar was also prepared as control specimen. The specimens were immersed in Sodium Chloride solution up to 18 months. The evaluation was done by visual observation, ultrasonic pulse velocity and mass change before and after exposure. The mortar was then split into two and sprayed with $0.1 \mathrm{~N}$ Silver Nitrate solution to see the depth of penetration. The test results revealed that biomass mortar showed high resistance to chloride penetration as compared to OPC mortar due to the reduction of cement content in the mixture. Besides, the reactive silica from nano POFA produced more crystalline formation thus, reduced the porosity and crack within the biomass mortar.
\end{abstract}

\section{Introduction}

The ordinary Portland cement (OPC) still continues to be the most commonly used in construction field. Many studies have shown that OPC gives poor performance in resistance to extreme climate and chemical condition [1-3]. Moreover, it processes and releases a large amount of green house gasses, i.e. carbon dioxide $\left(\mathrm{CO}_{2}\right)$ into the atmosphere. The need towards sustainability and sustainable environment has made the use of pozzolanic material in construction popular. Palm oil fuel ash is generally known as one of the 
pozzolanic material from natural waste. By 2014, Malaysia has recorded a staggering 5.39 million hectares of oil palm plantations, an increase of $11.0 \%$ from the previous 4.85 million hectares in 2010 [4]. Recent research has utilized the use of oil palm biomass waste on the mechanical properties of mortar [5]. As a new material for construction, very little research has been conducted on the durability of biomass mortar particularly with reference to chloride resistance. The durability of mortar is an important requirement for the performance in aggressive environments throughout its design life period.

\subsection{Materials}

The cement used in this study complies with Portland cement Type I. Palm Oil Fuel Ash (POFA) was obtained from the burning of palm oil shell and husk (in equal volume) from a southern part of Malaysia. The POFA collected were processed until nanoparticles size [6]. The Oil Palm Kernel Shell was used as sand replacement. The Oil Palm Fibre added was $7 \%$ by the volume of binder. The mortar was then known as biomass mortar [5].

\subsection{Testing Procedures}

All mortar specimens were prepared with sand to binder with the ratio of $3: 1$, whereby the sand was prepared into saturated surface dried condition. The mixing was carried out in a room temperature. The mix proportions are based on weight of materials according to BS EN 998-1:2010 [7]. The test specimens of $70 \times 70 \times 70 \mathrm{~mm}$ cubes were prepared as described in ASTM C109-13 [8]. Chloride ion penetration test was conducted to study the effect of chloride ion to mortar specimens. The test was conducted in accordance with ASTM C1202 'Electrical Indication of Concrete's Ability to Resist Chloride Ion Penetration' [9]. The specimens were immersed in $2.5 \%$ sodium chloride solution for 1,2 , $3,6,9,12$ and 18 months. The chloride concentration used in this study is similar to the one used by Ariffin (2012) and Hassan (2015) [10,11]. In addition, the ACI Committee 222R01 (2001) suggested that the concentration of water soluble chloride ion above $0.2 \%$ of Portland cement mass can accelerate the corrosion in the environment where moisture and oxygen are available [12]. At the specific test age, the specimens were split into two halves and the cross sections were sprayed with 0.1 silver nitrate solution. The surface of the specimens will changed to white colour as an indication the effect of chloride ions. The changes in mass were determined to monitor the chloride ion resistance during exposure.

\section{Results and Discussion}

\subsection{Compressive Strength}

Fig. 1 shows the compressive strength comparison of the OPC and biomass mortars. As the age of water curing increases, the compressive strength of OPC and biomass mortars are increases. This is due to the continuous hydration process and pozzolanic reaction occurred in the mortars. At 1 month curing, the compressive strength of biomass mortar increases by $24 \%$ as compared to OPC mortar. This is due to the second production of C-S-H gel from pozzolanic reaction. After 1 year of curing, the OPC and biomass mortars show compressive strength of $33.64 \mathrm{MPa}$ and $47.01 \mathrm{MPa}$, respectively. Despite the stronger bond produced and filler packing effect, the fibre in biomass mortar help to distribute the load and increase the bond between binder and fine aggregates resulting in an increase in the compressive strength. The compressive strengths obtained at the age of 1 year were approximately $28 \%$ higher than the target required design strength of $30 \mathrm{MPa}$. This 
continual increase in strength even after 1 year indicates that the biomass mortar does not deteriorate once the OPKS aggregates are encapsulated into the mortar matrix. Similar trends were reported for OPKS as coarse aggregates in the literature [13].

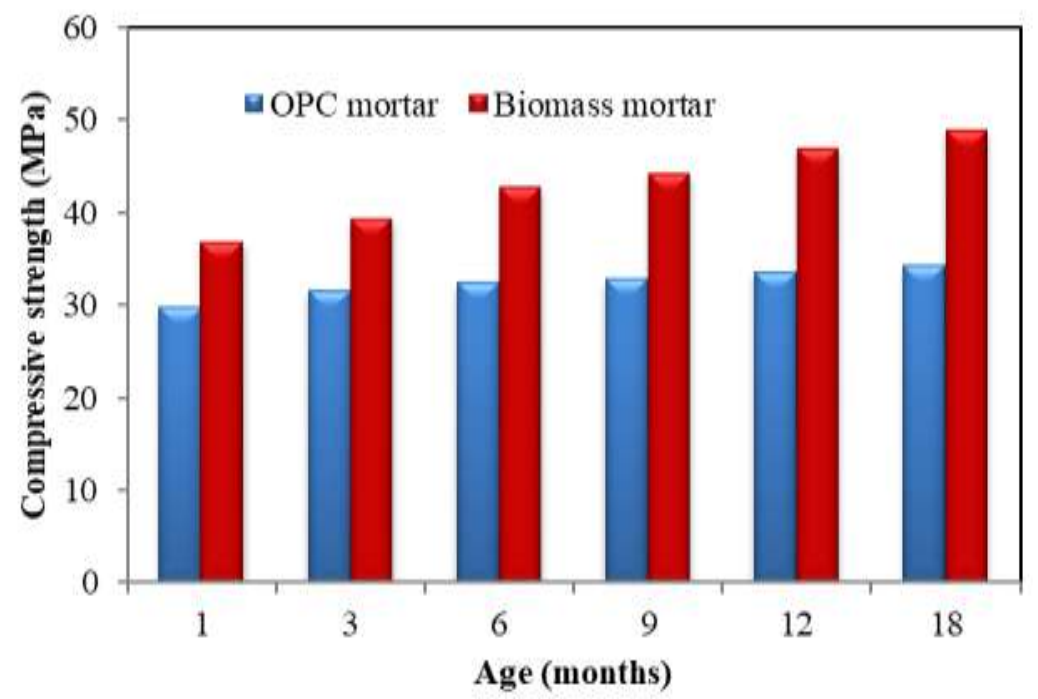

Fig 1 Strength development of OPC and biomass mortars

\subsection{Mass Change}

Fig. 2 shows the mass change of OPC and biomass mortars after immersion in sodium chloride $(\mathrm{NaCl})$ solution. It can be seen that the mortars had gained some mass when immersed in sodium chloride. The figure shows sudden increase in mass for OPC and biomass mortars to $0.9 \%$ and $0.4 \%$ from initial mass after 28 days immersion in solution, respectively. Similar results were obtained for immersion after 18 months in which the mass for OPC and biomass mortars gained $4.9 \%$ and $2.1 \%$ from initial mass, respectively. At the end of immersion, the mass became almost constant and steady. The mass change of OPC and biomass mortars was related to the ability of specimens to absorb the solution. In water absorption test conducted, biomass mortar has lower water absorption compared with OPC mortar. As a result, the mass of OPC mortar has higher percentage of mass change compared with biomass mortar. Similar findings on chloride penetration were also reported by previous research $[14,15]$.

It can be observed that the rate of decrease in penetration was higher in biomass mortar. The permeability resistance of mortar containing NPOFA was about two times that of OPC mortar. This is due to pore refinement within the mortar micro structure by NPOFA, or the transformation of large permeable pores to a smaller pore by the pore refinement of the fine particle and C-S-H gel produced from the hydration process. Therefore, these suggest that the resistance of chloride ion penetration of mortar can be significantly increased with the use of high volume NPOFA replacement. Likewise, high volume NPOFA changes the distribution of cement particle in the matrix, thus producing a decrease in the capillary network as well as reducing the average capillary pore size due to the gradual pozzolanic reaction and cement hydration process. Therefore, it is generally accepted that the incorporation of pozzolanic materials improves the resistance of chloride penetration. This 
is mainly due to the reduction in the permeability, particularly to chloride ion transportation of the blended cement mortar.

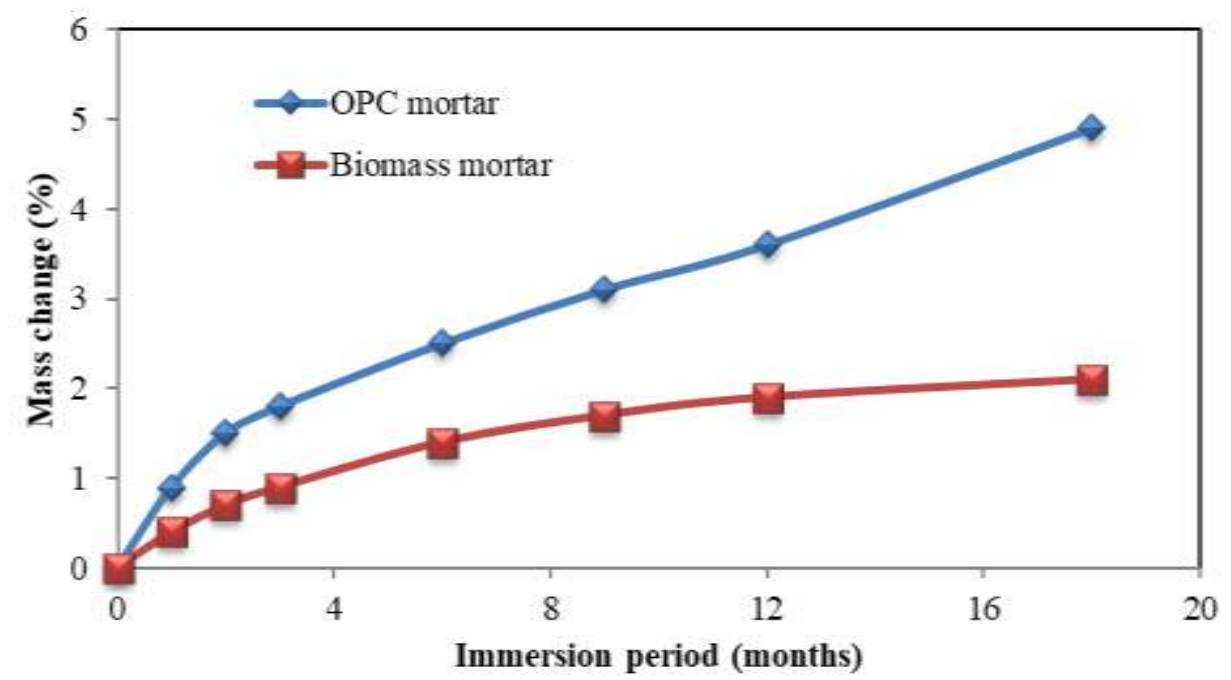

Fig 2 Mass change of OPC and biomass mortars in $\mathrm{NaCl}$

After a certain period of designated immersion time, the specimens were taken out from the solution and tested. The specimen was sprayed with $0.1 \mathrm{~N}$ silver nitrate solutions to determine the penetration of chloride ions. Fig. 3 shows the effect of chloride on OPC and biomass mortars. The average depth of chloride penetration for the OPC mortar was 15 $\mathrm{mm}$. On the other hand, for biomass mortar the depth was $3 \mathrm{~mm}$. These results show that chloride ions penetrate more in OPC mortar compared with biomass mortar. This is most likely because the biomass mortar contains pozzolanic material that generates more $\mathrm{C}-\mathrm{S}-\mathrm{H}$ gel that makes the mortar denser and less permeable.
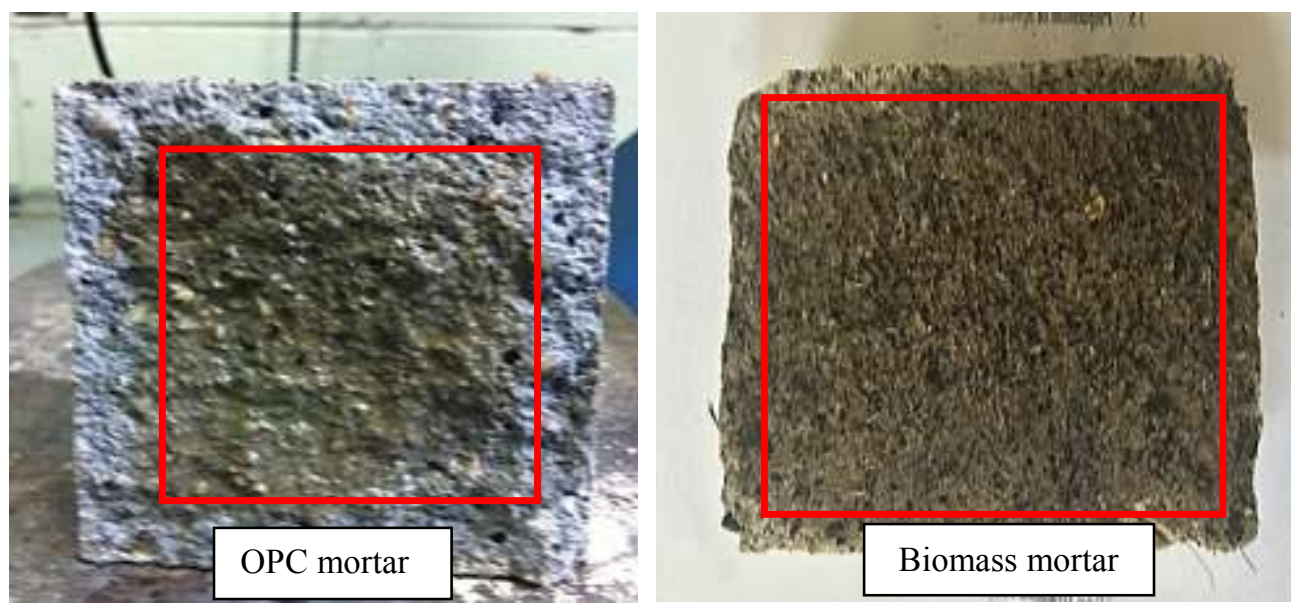

Fig 3 Mortars sprayed with 0.1 silver nitrate 


\subsection{Microstructure Analysis}

The SEM and XRD images of OPC and biomass mortars samples after 18 months of immersion in $\mathrm{NaCl}$ solution are shown in Figs. 4 and 5, respectively. It can be seen from the figures, that there are more voids presented inside the OPC mortar compared with the biomass mortar. Fewer voids were observed from the biomass mortar due to the gradual formation of C-S-H gel from the secondary reaction between reactive silica and $\mathrm{Ca}(\mathrm{OH})_{2}$ available from cement hydration. Therefore, higher chloride ions can penetrate into the OPC mortar thus chloride mineral is shown in the EDX analysis. Meanwhile, there is no chloride mineral detected in the biomass mortar due to the dense and less porosity of the mortar. Besides, the NPOFA materials not only generating more C-S-H gel but also act as filler that reduce the size of pore structure of mortar. Furthermore, the rough surface and irregular shape of OPKS used increase the interlocking between the fine aggregates and binder paste. The inclusion of OPF also increases the interlocking by bridging the paste and preventing minor cracks from occurring.

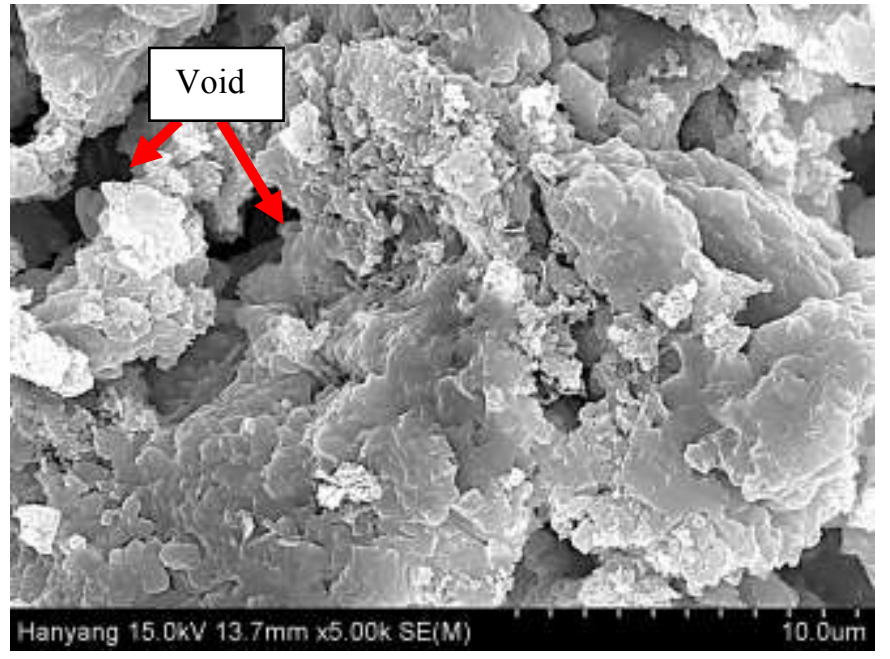

Fig 4 SEM and EDX images of OPC mortar in $\mathrm{NaCl}$

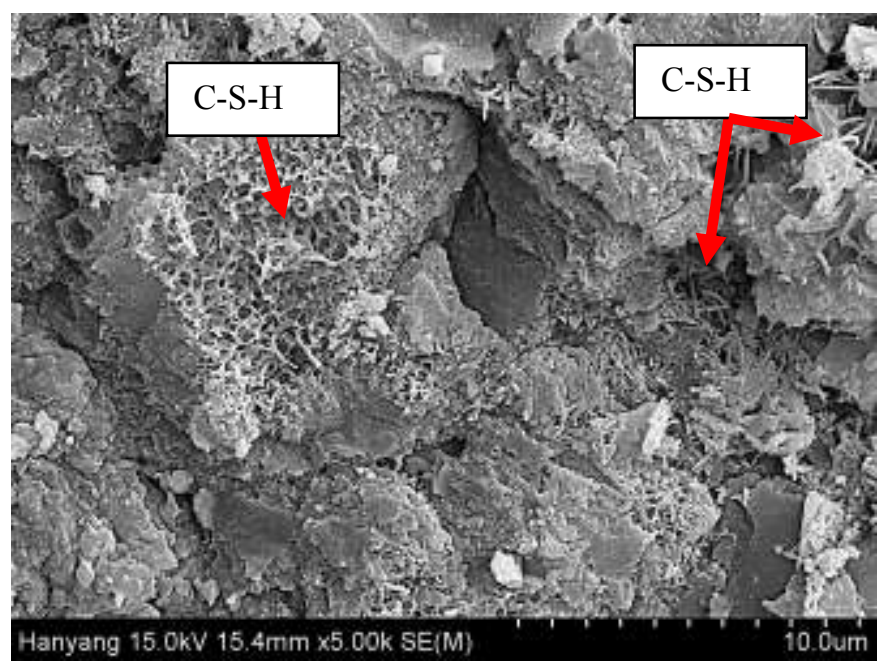

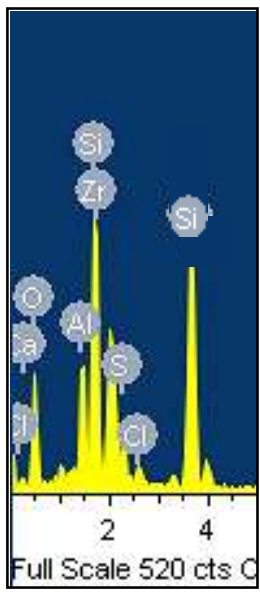

EDX

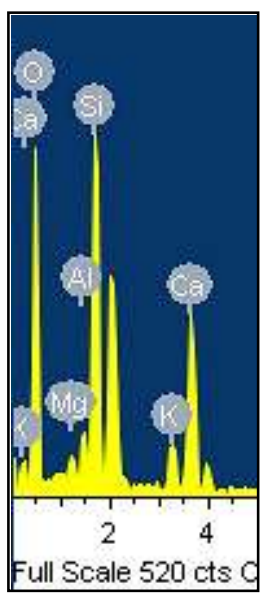

EDX

Fig $5 \mathrm{SEM}$ and EDX images of biomass mortar in $\mathrm{NaCl}$ 


\section{Conclusion}

The chloride ion penetration test revealed that biomass mortar offers superior resistance to the ion penetration than the OPC mortar. This is attributed to the micro filling ability and pozzolanic characteristic of the binder. Biomass mortar did not show any changes in appearance and dimension when exposed to chloride solution. The depth of chloride penetration for OPC mortar was $15 \mathrm{~mm}$ while for the biomass mortar was only $3 \mathrm{~mm}$. Besides, the compressive strength of biomass mortar increases by $24 \%$ as compared with OPC mortar at 1 month curing. The compressive strengths obtained at the age of 1 year were approximately $28 \%$ higher than the target required design strength of $30 \mathrm{MPa}$. This continual increase in strength even after 1 year indicates that the biomass mortar does not deteriorate once the OPKS aggregates are encapsulated in the mortar.

The authors are grateful to the Ministry of Higher Education, Malaysia (MOHE) and Research Management Centre (RMC), Universiti Teknologi Malaysia (UTM) for financial support under grant GUP Q.J130000.7322.4B216. The authors are also thankful to the staff of Structures \& Materials Laboratory and Faculty of Civil Engineering and Department of Architectural Engineering, Hanyang University for the support throughout the study.

\section{References}

1. M. A. R. Bhutta, N. F. Ariffin, M. W. Hussin, and N. S. A. Hasanah, "Sulfate and sulfuric acid resistance of geopolymer mortars using waste blended ash. Jurnal Teknologi”, 3, 1-5 (2013)

2. M. W. Hussin, N. F. Ariffin, M. A. R. Bhutta, and N. H. A. S. Lim, "Study on Dry-Wet Cyclic Resistance of Geopolymer Mortars Using Blended Ash from Agro-Industrial Waste. In Proceeding of Third International Conference on Sustainable Construction Materials and Technologies", August 2013, Kyoto, Japan (2013)

3. J. Hill, E. A. Byars, J. H. Sharp, C. J. Lynsdale, J. C. Cripps, and Q. Zhou, "An experimental study of combined acid and sulfate attack of concrete. Cement and Concrete Composites", 25(8), 997-1003 (2003)

4. Malaysian Palm Oil Board, (MPOB) (2015, December 1), "Economic and industry development devision. Oil Palm Planted Area", Available at: (http://bepi.mpob.gov.my/index.php/statistics/area.html)

5. N. H. A. S. Lim, M. W. Hussin, A. S. M. Rahman, M. A. R. Bhutta, N. F. Ariffin, N. H. A. Khalid, and M. Samadi, "Properties of mortar containing high volume palm oil biomass waste. Advanced Materials Research", 1113, 578-585 (2015)

6. N. H. A. S. Lim, M. A. Ismail, H. S. Lee, M. W. Hussin, A. R. M. Sam, and M. Samadi, "The effects of high volume nano palm oil fuel ash on microstructure properties and hydration temperature of mortar. Construction and Building Materials", 93, 29-34 (2015)

7. British Standard Institution, Specification for mortar for masonry. Rendering and plastering mortar. BS EN 998-1:2010, (2010)

8. ASTM C109, 2013, Standard test method for compressive strength of hydraulic cement mortars, Annual Book of ASTM Standards, American Society for Testing and Materials (2013)

9. ASTM C1202, Electrical indication of concrete's ability to resist chloride ion penetration, Annual Book of ASTM Standards, American Society for Testing and Materials (2012)

10. N. F. Ariffin, "Durability of geopolymer mortars using agro-industrial waste", Thesis, Universiti Teknologi Malaysia (2012) 
11. I. O. Hassan, "Self consolidating high performance palm oil fuel ash and pulverised burnt clay blended concrete", Ph.D. Thesis, Universiti Teknologi Malaysia (2015)

12. ACI Committee 222R, Protection of metals in concrete against corrosion. American Concrete Institute, (2001)

13. D. C. L. Teo, M. A. Mannan, V. J. Kurian and C. Ganapathy, "Lightweight concrete made from oil palm shell (OPS): Structural bond and durability properties. Building and Environment", 42, 2614-2621 (2007)

14. D. Mujah, "Compressive strength and chloride resistance of grout containing ground palm oil fuel ash. Journal of Cleaner Production", 112, 712-722 (2015)

15. P. Chindaprasirt, S. Rukzon, and V. Sirivivatnanon, "Resistance to chloride penetration of blended Portland cement mortar containing palm oil fuel ash, rice husk ash and fly ash. Construction and Building Materials", 22, 932-938 (2008) 